\title{
$\triangle$ MST and the Regulation of Cardiac CSE and OTR Expression in Trauma and Hemorrhage
}

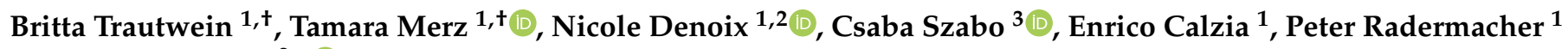 \\ and Oscar McCook $2, *$ D \\ 1 Institute for Anesthesiological Pathophysiology and Process Engineering, Ulm University Medical Center, \\ 89081 Um, Germany; britta@lukaschewski.de (B.T.); tamara.merz@uni-ulm.de (T.M.); \\ nicole.denoix@uni-ulm.de (N.D.); enrico.calzia@uni-ulm.de (E.C.); peter.radermacher@uni-ulm.de (P.R.) \\ 2 Clinic for Psychosomatic Medicine and Psychotherapy, Ulm University Medical Center, 89070 Ulm, Germany \\ 3 Department of Science and Medicine, University of Fribourg, 1700 Fribourg, Switzerland; \\ csaba.szabo@unifr.ch \\ * Correspondence: oscar.mccook@uni-ulm.de \\ + Equally contributed.
}

Citation: Trautwein, B.; Merz, T.; Denoix, N.; Szabo, C.; Calzia, E.;

Radermacher, P.; McCook, O

$\triangle \mathrm{MST}$ and the Regulation of Cardiac CSE and OTR Expression in Trauma and Hemorrhage. Antioxidants 2021, 10, 233. https://doi.org/10.3390/ antiox10020233

Academic Editors: João Vicente and Alessandro Giuffrè

Received: 17 December 2020

Accepted: 1 February 2021

Published: 3 February 2021

Publisher's Note: MDPI stays neutral with regard to jurisdictional claims in published maps and institutional affiliations.

Copyright: (c) 2021 by the authors. Licensee MDPI, Basel, Switzerland. This article is an open access article distributed under the terms and conditions of the Creative Commons Attribution (CC BY) license (https:// creativecommons.org/licenses/by/ $4.0 /)$.

\begin{abstract}
Genetic deletion of 3-mercaptopyruvate sulfurtransferase (MST) is known to result in hypertension and cardiac hypertrophy in older mice, and is associated with increased anxiety-like behaviors. Endogenous hydrogen sulfide $\left(\mathrm{H}_{2} \mathrm{~S}\right)$ produced by MST in the mitochondria is also known to be involved in physiological and cellular bioenergetics, and its dysfunction associated with depressive behavior and increased cardiovascular morbidity. Interestingly, early life stress has been shown to lead to a significant loss of cystathionine- $\gamma$-lyase (CSE) and oxytocin receptor (OTR) expression in the heart. Thus, we were interested in testing the hypothesis of whether genetic MST mutation ( $\triangle \mathrm{MST}$ ) would affect cardiac CSE and OTR expression and affect the mitochondrial respiration in a clinically relevant, resuscitated, mouse model of trauma and hemorrhagic shock. In $\triangle$ MST mice, we found a reduction of CSE and OTR in both the naive as well as injured state, in contrast to the wild type (wt) controls. Interestingly, the $\triangle \mathrm{MST}$ showed a different complex IV response to injury than the wt controls, although our claims are based on the non-demonstrated assumption that naive wt and naive $\triangle \mathrm{MST}$ mice have comparable complex IV activity. Finally, hemorrhagic shock led to a reduction of CSE and OTR, confirming previous results in the injured mouse heart. To date, the exact mechanisms of the cardiac interaction between $\mathrm{H}_{2} \mathrm{~S}$ and OT are not clear, but they point the way to potential cardioprotective therapies.
\end{abstract}

Keywords: hydrogen sulfide; oxytocin; mitochondria; early life stress; psychosomatic; anxiolytic

\section{Introduction}

The neuroendocrine oxytocin (OT) system and the gasotransmitter hydrogen sulfide $\left(\mathrm{H}_{2} \mathrm{~S}\right)$, endogenously produced by cystathionine $\beta$-lyase (CSE), cystathionine $\gamma$-synthase (CBS), and 3-mercaptopyruvate-sulfurtransferase (MST), have been shown to have parallel roles in the heart in response to trauma. OT and $\mathrm{H}_{2} \mathrm{~S}$ are relevant in models of both psychological and physical trauma, displaying cardio-protective effects [1].

Genetic deletion (ko) of MST has resulted in hypertension and cardiac hypertrophy, at least in aged mice [2]; furthermore, it has been associated with increased anxietylike behaviors [3]. We investigated the effects of a genetic MST mutation ( $\triangle \mathrm{MST})$ in a resuscitated mouse model of traumatic-hemorrhagic shock, and found no significant differences in hemodynamics, gas exchange, metabolism, acid base status, or survival between $\triangle \mathrm{MST}$ and the respective wild type groups [4].

Hydrogen sulfide $\left(\mathrm{H}_{2} \mathrm{~S}\right)$ is reported to be cardioprotective in ischemia reperfusion injury [5-8], and endogenous $\mathrm{H}_{2} \mathrm{~S}$ produced by MST localized to the mitochondria has been reported to support basal, physiological, and cellular bioenergetics function [9]. In response 
to osmotic balance stress, $\mathrm{H}_{2} \mathrm{~S}$ can stimulate OT release from magnocellular neurons of the paraventricular nuclei (PVN) in the hypothalamic regulation of blood volume and pressure. Hemorrhagic shock (HS) is the highest acute blood volume change in trauma, and can lead to hypoxic events in the brain [10]. In addition, Amini-Khoei et al. demonstrated that depressive-like behavior caused by early life stress (ELS) is associated with mitochondrial dysfunction, and that administration of oxytocin (OT) improves mitochondrial function and behavior [11]. ELS is known to increase cardiovascular morbidity [12,13], and moreover, ELS leads to a significant loss of CSE and oxytocin receptor (OTR) expression in the heart [14]. These results in the ELS model are similar to the findings we report in an acuteon-chronic trauma model: the interaction of the $\mathrm{H}_{2} \mathrm{~S}$ and OT system in cardiovascular injury. Cardiac OTR was significantly downregulated, and the downregulation was even more pronounced in mice with genetic CSE deletion, but it could be restored by exogenous $\mathrm{H}_{2} \mathrm{~S}$ administration (GYY4137) [15]. Furthermore, naive CSE knock out (ko) mice had lower levels of OTR [1], and similarly, naive mice with a genetic deletion of OTR presented with a reduction of CSE expression [14]. Psychological stress can reportedly dysregulate OTR expression [16], and trauma leads to cardiovascular co-morbidities, which increase morbidity and mortality in intensive care patients $[1,17,18]$. Trauma can be a result of either (or both) a deep emotional pain, and / or a life-threatening event (psychological) or a physiological injury or impact against the body (physical). Recent research has indicated that both physical [15] and psychological [14] trauma share physiological properties [1,19].

The dearth of published data on the role of MST in the heart and our interest in the role of CSE and OTR in both psychological and physical trauma motivated us to evaluate post hoc cardiac samples from a previous experiment [4] and concurrent naive animals. Our goal was to focus on the role of OTR and CSE, due to their interaction in fluid shifts and in psychological stress, which is relevant in light of the anxiolytic role of MST. Therefore, this study tested the hypothesis of whether the $\triangle$ MST phenotype affects the cardiac CSE/OTR expression, and whether this coincides with alterations of mitochondrial respiration.

\section{Materials and Methods}

The study protocol was authorized by the federal authorities for animal research of the Regierungspräsidium Tübingen (approved animal experimentation number: 1190), BadenWürttemberg, Germany, and the Animal Care Committee of the University of Ulm, BadenWürttemberg, Germany. Experiments were performed in adherence with the National Institutes of Health Guidelines on the Use of Laboratory Animals and the European Union "Directive 2010/63 EU on the protection of animals used for scientific purposes". C57BL/6J mice were received from Charles River laboratories Germany (Sulzbach, Germany), and $\triangle \mathrm{MST}$ as previously reported [4]. The generation of $\triangle \mathrm{MST}$ mice has previously been described in detail [20]. Briefly, $\triangle$ MST mice were generated by a disruption of the MST gene by gene trapping, using the Omnibank gene trap vector containing a dominant splice acceptor site that integrated upstream of the MST protein coding region in the mouse genome in C57Bl6 embryonic stem cells. The resulting animals are characterized by reduced MST mRNA expression in many tissues (lung, muscle, testis) [20] and reduced MST protein levels in the lung, spleen, and pancreas [20,21]. MST protein levels in the kidney and liver are not affected by the mutation [20,21], and to the best of our knowledge, the effects of this mutation on MST expression in the heart have not been investigated to date.

\subsection{Polytrauma Model}

At the beginning of the experiment, mice were anesthetized with inhaled sevoflurane (Sevorane, Abbott, London, UK) and subcutaneous buprenorphine (Temgesic, Reckitt Benckiser, Slough, UK). Then, a sham procedure or blunt chest trauma (Txt), generated by a midthoracal, single blast wave, as described previously, was induced [4]. Afterwards, all mice received intraperitoneal ketamine (Ketanest-S, Pfizer, New York, NY, USA), midazolam (Midazolam-ratiopharm, Ratiopharm, Ulm, Germany), and fentanyl (Fentanyl-hameln, 
Hameln Pharma Plus GmbH, Hameln, Germany), and were placed in a mouse intensive care unit as previously described $[4,22,23]$, comprising lung-protective mechanical ventilation, hemodynamic monitoring and management, and closed-loop temperature control. All animals underwent $1 \mathrm{~h}$ of hemorrhagic shock (HS), induced by blood withdrawal adjusted to either the maximum volume $(30 \mu \mathrm{L} / \mathrm{g}$ body weight) or a mean arterial blood pressure (MAP) of $35 \mathrm{mmHg}$ [23]. Afterwards, mice were resuscitated with shed-blood, colloid fluids (hydroxyethyl starch, Tetraspan, Braun Medical), or, if necessary, continuous norepinephrine infusions to maintain MAP $\geq 50 \mathrm{mmHg}$ [22]. Systemic hemodynamic parameters and static thoracopulmonary compliance were recorded hourly; blood gas tensions, acid-base status, glycemia, and lactatemia were assessed at the end of the $4 \mathrm{~h}$ period of resuscitation [4]. At the end of the experiment, animals were exsanguinated, and the blood and organs were sampled. The number of animals per group was as follows: wild type hemorrhagic shock (wt HS) $=10$, wt HS with blunt chest trauma (wt HS Txt) $=10$, $\Delta \mathrm{MST} H S=8, \Delta \mathrm{MST} H S+\mathrm{Txt}=8$. Naive animals (wt: $n=9, \Delta \mathrm{MST}: n=9)$ were anesthetized with sevoflurane (Sevorane, Abbott, London, UK) and buprenorphine (Temgesic, Reckitt Benckiser); mid-line laparotomy was performed, and animals were sacrificed via venous exsanguination [15]. The heart was harvested, and the apex placed in ice-cold Custodiol for mitochondrial respiration measurements. The remaining heart was cut transversally and formalin-fixed for immunohistochemistry [4,15].

\subsection{Mitochondrial Respiration}

Mitochondrial respiratory capacity was measured using high-resolution respirometry with a Clark electrode-based system (Oxygraph-2k respirometer, Oroboros instruments Corp., Innsbruck, Austria), as previously described [23,24]. Immediately post mortem, heart tissue was mechanically homogenized in the respiration medium (Mir05/EGTA = $0.5 \mathrm{mM}, \mathrm{MgCl}_{2} \cdot 6 \mathrm{H}_{2} \mathrm{O}=3 \mathrm{mM}$, lactobionic acid $=60 \mathrm{mM}$, taurine $=20 \mathrm{mM}, \mathrm{KH}_{2} \mathrm{PO}_{4}=$ $10 \mathrm{mM}$, HEPES $=20 \mathrm{mM}$, sucrose $=110 \mathrm{mM}$, and bovine serum albumin $=1 \mathrm{~g} / \mathrm{L})$ and $1.5 \mathrm{mg}$ of tissue were transferred to the Oxygraph chamber. A defined sequence of substrates or inhibitors were added to assess various states of mitochondrial respiratory capacity. The activity of complex I was measured after the addition of $10 \mathrm{mM}$ pyruvate, $10 \mathrm{mM}$ glutamate, $5 \mathrm{mM}$ malate, and $5 \mathrm{mM}$ ADP; in order to assess the maximum oxidative phosphorylation (OxPhos), $1 \mathrm{mM}$ octanoyl-carnitine and $10 \mathrm{mM}$ succinate were added. Leak compensation flux was assessed after the inhibition of ATP-synthase by $2.5 \mu \mathrm{M}$ oligomycin; the maximum respiratory activity of the electron transfer system in the uncoupled state (ETS) was measured after titrating carbonyl cyanide-4-(trifluoromethoxy)phenylhydrazone (FCCP; final concentration $=1.5 \mu \mathrm{M}$ ). The activity of complex IV was determined by adding $2 \mathrm{mM}$ ascorbate and $0.5 \mathrm{mM} \mathrm{N}, N, N^{\prime}, N^{\prime}$-Tetramethyl-p-phenylenediamine dihydrochloride (TMPD) [4,22].

\subsection{Immunohistochemistry}

We specifically decided to prioritize immunohistochemistry (IHC) analysis over Western blot (WB), because WB would only limit the amount of information that could be had, in that it would obviate the topographical landscape and specific localization of the protein of interest would be lost (e.g., vascular MST expression depicted in Figure 1A,C,E). We have previously shown that the quantification of protein via IHC directly correlates with the quantification by Western blot $\left(p=0.001, R^{2}=0.76\right)$ [25]. In Wigger et al., protein quantification via both IHC and WB also revealed the same result [14]. Quantification of protein expression via IHC can be inaccurate when using fluorescent antibodies, which is why we rely on a red chromogen and permanent mount, which prevents decaying of the signal, as would be the case with fluorescence. Furthermore, an often-neglected point is that it is well-known that WB is open to contamination by whole blood products containing the $\mathrm{H}_{2} \mathrm{~S}$ endogenous enzymes [26] and OTR [27]. Thus, all methods that require tissue homogenization like $\mathrm{WB}$ are prone to generate inaccurate results due to potential contamination, unless previously perfused, which is very rarely done. 

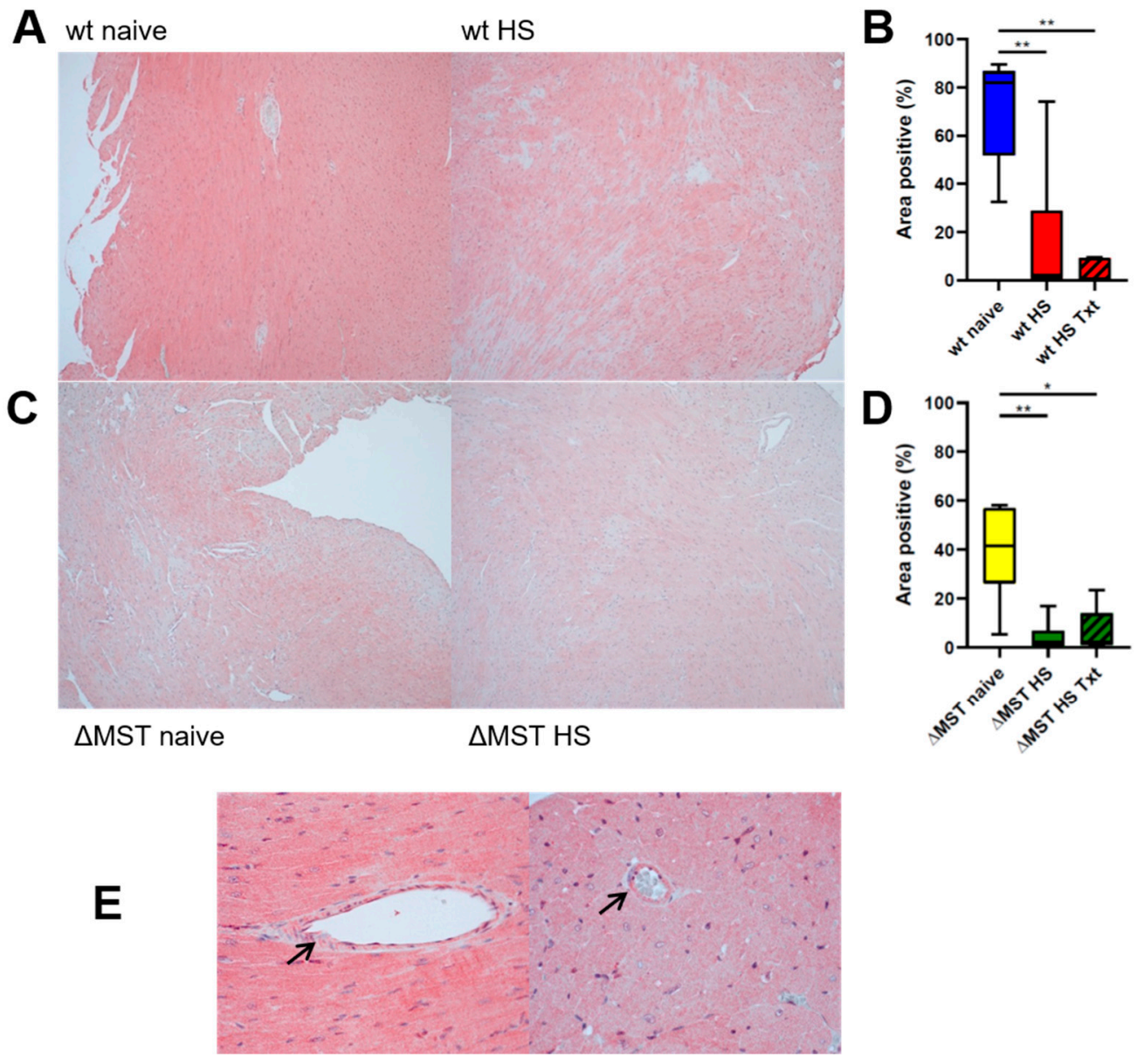

Figure 1. Cardiac 3-mercaptopyruvate sulfurtransferase (MST) protein expression. (A) Exemplary pictures for MST expression in cardiac tissue from naive and injured wild-type (wt) mice (magnification $=10 \times$ ). (B) Quantification of MST expression (wt naive $n=8$, wt hemorrhagic shock (HS) $n=10$, wt HS blunt chest trauma (Txt) $n=7$ ). (C) Exemplary pictures for MST expression in cardiac tissue from naive and injured genetic MST mutation $(\triangle \mathrm{MST})$ mice (magnification $=10 \times$ ). (D) Quantification of MST expression ( $\triangle$ MST naive $n=8, \Delta$ MST HS $n=8, \Delta$ MST HS Txt $n=8$ ). Boxplots depict the median and interquartile range; whiskers represent the minimum and maximum values. ${ }^{*} p<0.05$, ** $p<0.01$. (E) Exemplary pictures of MST expression in large $($ left $=40 \times)$ and small $($ right $=64 \times)$ coronary vessels (arrows).

As previously described [15] hearts were formalin-fixed, dehydrated, embedded in paraffin, and then cut into $3 \mu \mathrm{m}$ sections. The slides were deparaffinized, rehydrated, and heat-induced antigen retrieval using citrate buffer $\mathrm{pH} 6.0$ was performed. Slides were then blocked with $10 \%$ goat serum. To assess the expression of CSE, OTR, and MST in the heart, the following primary antibodies were used: anti-CSE (rabbit polyclonal; Proteintech, 12217-1-AP, Rosemont, IL, USA), anti-OTR (rabbit polyclonal; Proteintech, 23045-1-AP), and anti-MST (rabbit polyclonal; Sigma, HPA001240, Saint Louis, MO, USA) [14,15]. Primary antibodies were detected by a secondary antibody (goat-anti-rabbit $\operatorname{IgG}$ conjugated to alkaline phosphatase; Jackson ImmunoResearch, Cambridge, UK). Antibodies were visualized with a red chromogen (Dako REAL Detection System Chromogen Red, Dako, Glostrup, Denmark), and tissue was counterstained with Mayers hematoxylin (Sigma). The staining was evaluated with the Zeiss Axio Imager A1 microscope and the Axio Vision 4.8 software (CSE, OTR) and Zeiss Zen 3.0 (MST) (Zeiss, Oberkochen, Germany). Two distinct $800,000 \mu \mathrm{m}^{2}$ regions were quantified and presented as densitometric sum red or area $\%$ [15]. 


\subsection{Statistical Analysis}

All data are presented as medians (25th and 75th percentile) unless stated otherwise. Mitochondrial respiratory capacity was analyzed with a two-way ANOVA, followed by a post-hoc Tukey test. For CSE and OTR immunohistochemistry, normal distribution was confirmed with the Kolmogorov-Smirnov test, and differences between groups were analyzed using an ordinary one-way ANOVA and a post-hoc Holm-Sidak test. For MST, normal data distribution was excluded with the Kolmogorov-Smirnov test, and differences between groups were analyzed using the Kruskal-Wallis ANOVA on ranks, followed by a post-hoc Dunn test for two-tailed multiple comparisons. Quantitative relations between mitochondrial function, CSE, and OTR expression were assessed by measuring the Pearson coefficient of correlation. For this purpose, data from individual animals were pooled, no matter the group assignment. A result of $p<0.05$ was considered as statistically significant. Quantitative graphical presentations and statistical analyses were performed with GraphPad Prism 8 (Graphpad Software Inc., San Diego, CA, USA).

\section{Results}

We detected MST in the heart and coronary vasculature of our $\triangle \mathrm{MST}$ mice (see Figure 1A,E). MST expression was significantly reduced after injury in both wt and $\Delta$ MST animals compared to the respective naive group (see Figure 1B,D). There was no difference between naive wt and $\triangle \mathrm{MST}$ mice with Kruskal-Wallis analysis of all six groups. When comparing only these two groups in a Mann-Whitney rank sum test, the MST reduction in $\Delta$ MST animals reaches statistical significance $(p=0.01)$.

CSE and OTR were constitutively expressed in cardiomyocytes of naive animals (see Figure 2A,C, left panel). In wt animals, HS and HS + Txt significantly reduced expression of cardiac CSE and OTR compared to naïve animals. $\triangle$ MST animals had significantly lower CSE and OTR expression already in the naive state, and no further reduction in MST expression after injury was observed (see Figure 2A-D). The $\Delta$ MST groups all had reduced CSE and OTR expression compared to naive wt. There was no difference in CSE and OTR expression between $\triangle \mathrm{MST}$ and wt after trauma (see Figure 2A-D). There was a direct, linear relationship between CSE and OTR expression in all animals, independent of the genetic background or injury (see Figure 2E).

In mechanically permeabilized heart tissue, the mitochondrial activity of complex IV was significantly elevated in both wt HS and wt HS Txt trauma groups compared to naive wt animals. $\triangle$ MST HS and $\triangle$ MST HS + Txt animals had similar complex IV activity levels to the wt naive animals. No significant intergroup differences could be shown in the remaining states of mitochondrial function (see Figure 3). 


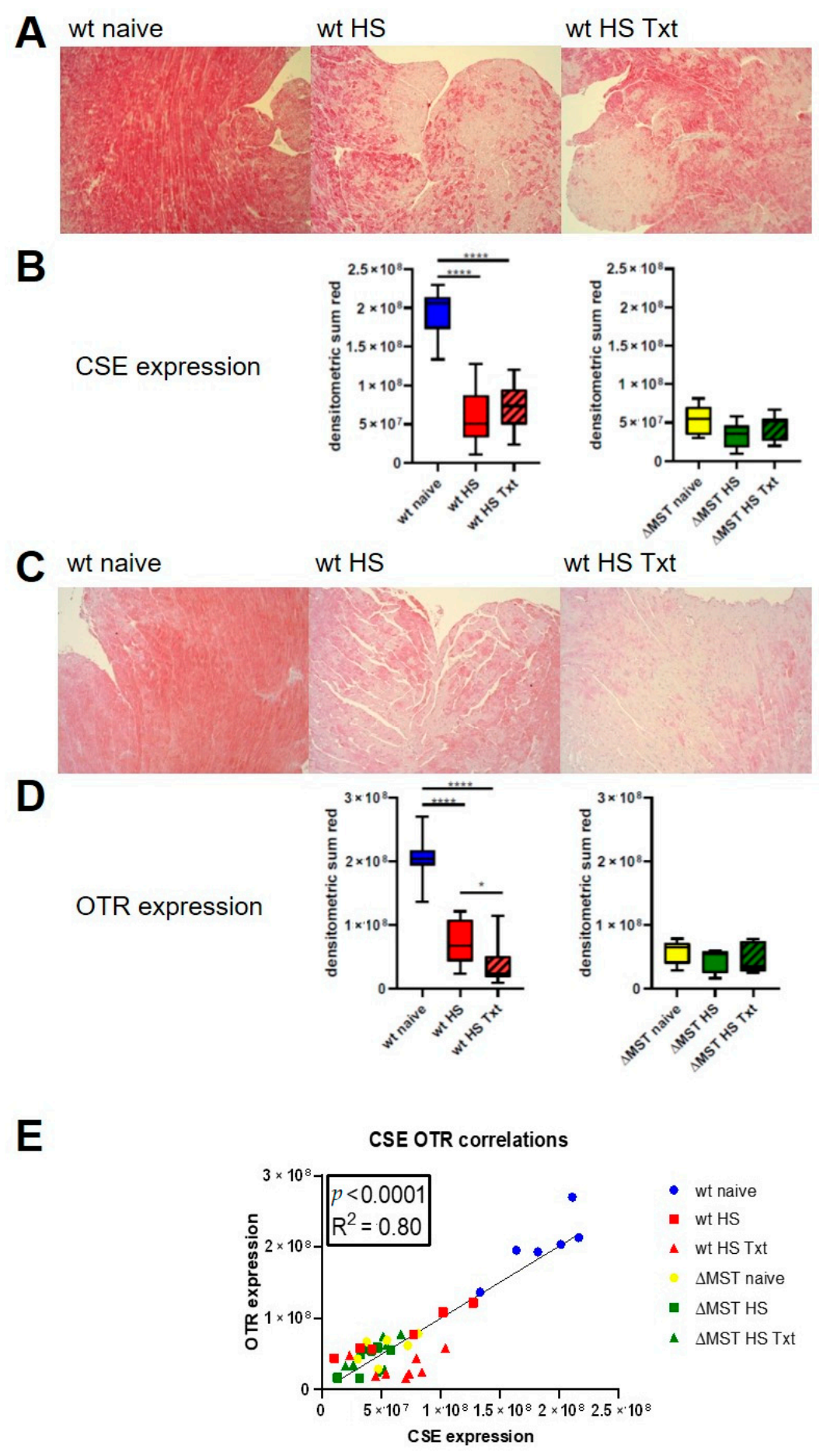

Figure 2. Cardiac cystathionine $\beta$-lyase (CSE) and oxytocin receptor (OTR) protein expression. (A) exemplary pictures for CSE expression in cardiac tissue from naive wt, wt HS, and wt HS Txt (magnification $=10 \times$ ). (B) Quantification of CSE expression (wt naive $n=9$, wt HS $n=10$, wt HS Txt $n=9, \Delta$ MST naive $n=9, \Delta$ MST HS $n=8, \Delta$ MST HS Txt $n=7$ ). Boxplots depict the median and interquartile range, and whiskers represent the minimum and maximum values. ${ }^{* * * *} p<0.0001$. (C) Exemplary pictures for OTR expression in cardiac tissue from naive wt, wt HS, and wt HS Txt (magnification $=10 \times$ ). (D) Quantification of OTR expression (wt naive $n=9$, wt HS $n=10$, wt HS Txt $n=10, \Delta$ MST naive $n=6, \Delta$ MST HS $n=8, \Delta$ MST HS Txt $n=7$ ). Boxplots depict the median and interquartile range, and whiskers represent the minimum and maximum values. ${ }^{*} p<0.05$, ****$p<0.0001$. (E) Direct linear relationship between CSE and OTR protein expression in wt, $\Delta \mathrm{MST}$ naive, and injured mouse hearts. 

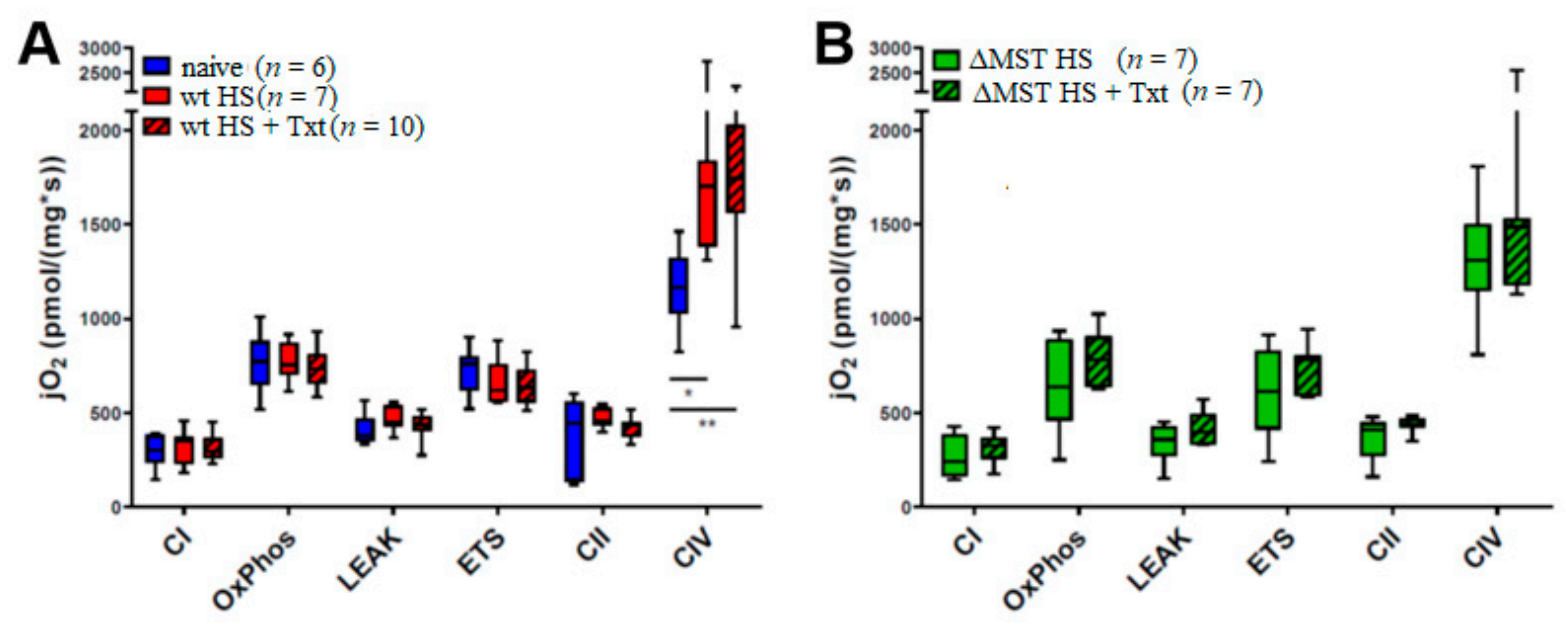

Figure 3. Mitochondrial respiratory capacity in the heart. (A) Wt animals. (B) $\triangle \mathrm{MST}$ animals. jO2: oxygen flux, CI: mitochondrial oxygen consumption after addition of substrates for the stimulation of complex I, OxPhos: maximum respiratory capacity in the coupled state, LEAK: mitochondrial oxygen consumption after inhibition of ATP synthase in the coupled state, ETS: maximum respiratory capacity in the uncoupled state, CII: mitochondrial oxygen consumption depending on the activity of complex II after inhibition of complex I, CIV: oxygen consumption after stimulation of complex IV. Boxplots depict the median and interquartile range, and whiskers represent the minimum and maximum values. ${ }^{* *} p<0.01,{ }^{*} p<0.05$.

\section{Discussion}

The main findings of this study were that (1) $\triangle$ MST mice had lower levels of MST in the heart than wt; (2) there was a downregulation of cardiac CSE and OTR expression in naïve $\triangle$ MST when compared to wt mice; (3) hemorrhagic shock induced (a) a cardiac mitochondrial upregulation in complex IV activity in wt animals and (b) a decrease of myocardial CSE and OTR expression in wt mice; (4) there was linear correlation between cardiac CSE and OTR expression, and that correlation holds true after injury.

Interestingly, MST was detected in the heart and coronary vasculature (see Figure 1C) of both wt and $\triangle \mathrm{MST}$ naive mice. However, $\triangle \mathrm{MST}$ mice presented with lower MST expression than the wt littermates. While both HS alone and the combination of HS and Txt further reduced cardiac MST, this difference between wt and $\triangle \mathrm{MST}$ was abolished by the challenge of HS with(out) Txt.

The naive $\triangle$ MST had lower CSE and OTR expression when compared to the wt mice. In contrast to our findings in the $\triangle$ MST mice, Peleli et al., using a global MST-ko model found no change in the expression of the endogenous CSE and CBS enzymes [2]. The difference in expression pattern may be attributed to the fact that we used a mutated MST mouse model in comparison to Peleli's global MST-ko. Nevertheless, Ahmad et al. using the same global MST-ko as Peleli et al., found lower endogenous CBS activity than in the wt animals in the liver [28], suggesting compartmentalization and varied regulation of the endogenous enzymes in different organs. Trauma induced a significant downregulation of CSE and OTR expression in the wt mouse heart upon hemorrhagic shock, but there was no additional loss of these enzymes in the $\triangle$ MST mice. Moreover, there was a significant direct linear relation between the of expression of CSE and OTR proteins, independent of the genotype of the mice (wt vs. $\triangle \mathrm{MST}$ ) and injury (see Figure 2E).

This begs the question of what mechanistically was at play in the $\triangle$ MST naive mice that led to the reduced CSE and OTR expression in the heart. Furthermore, it is not immediately apparent why there are reported differences in the expression pattern of the endogenous enzymes in these models, while it may in part be due to the different injuries evaluated (i.e., HS [4], myocardial ischemia/reperfusion (MIR) [2], and burn [28]). It may also be pointing to a very complex interaction of the endogenous enzymes in their response to injury. In fact, in an earlier study comparing genetically modified strains of the endogenous $\mathrm{H}_{2} \mathrm{~S}$ enzymes (CSE-ko, CBS partial ko, and $\triangle \mathrm{MST}$ mice), Ahmad et al. 
show inherent and organ-specific variability in the genetically modified strains' response to lipopolysaccharide (LPS) challenge [21]. Even though the expression patterns in the four organs evaluated (lung, kidney, liver, and spleen) were (mostly) similar, the few differences were striking: while in the $\triangle$ MST mice LPS increased CBS in the kidney only, it enhanced CBS expression in the spleen and lung in the wt mice, in contrast to the liver and kidney in the CSE-ko mice.

This is an intriguing variety of responses in the genetically modified strains, and suggests a very complex relationship among the three endogenous $\mathrm{H}_{2} \mathrm{~S}$-producing enzymes. In fact, ambivalent results are reported from the same group: on the one hand, the loss of MST conferred protection in MIR [2]; on the other hand, authors showed in a heart failure model that MST impaired mitochondrial respiration, which was ultimately associated with reduced exercise performance and increased cardiac dysfunction in their model [29].

In our study, in wt mice, the mitochondrial activity of complex IV was significantly elevated in both wt HS and HS Txt trauma groups when compared to naive animals, whereas the complex IV activity in $\triangle \mathrm{MST}$ groups in response to injury was similar to wt naive levels. We had previously reported that our data did not indicate compromised respiratory activity in any of the investigated tissues of the trauma groups [4]. When contrasting these results in the trauma groups to the wt naive state, as was done here, we were then able to clearly recognize a significant trauma-related compensatory mechanism at play in complex IV in wt animals (see Figure 3). No significant intergroup differences could be shown in the remaining states of mitochondrial function.

We did not assess any possible behavioral effects of the $\triangle \mathrm{MST}$ genotype, but the reduction of both CSE and OTR in the naive $\triangle$ MST mice may be related to the anxiolytic effects of MST reported by Nagahara et al. [3]. Nevertheless, Wigger et al. reported a similar loss of both CSE and OTR in the adult hearts of neonatal mice exposed to chronic, long-term maternal separation [14], an early life stress (ELS) model of psychosocial trauma. The loss of cardiac protein expression in response to psychological trauma is comparable to the effects of physical trauma reported here and previously [15]. Interestingly, the effects of psychosocial trauma were dependent on the stress dose: in the study from Wigger et al., short-term separation stress (STSS) had the opposite effect as long-term separation stress (LTSS) on cardiac OTR expression, upregulating it instead of downregulating it, which is speculated to mediate stress resilience in response to STSS. In contrast, LTSS rather seems to be associated with stress-induced vulnerability [14]. It is interesting to note that the $\triangle$ MST phenotype in the naive state leads to a similar loss of CSE and OTR as long-term ELS [2,3]. Similarly, both LTSS and a lack of MST are associated with increased anxiety and depressive-like behavior, mediated by alterations at the brain level $[3,14]$. Thus, the naive $\triangle \mathrm{MST}$ animals are characterized by lower CSE and OTR expression in the heart, which coincides with a pattern seen in both psychological and physical trauma, suggesting an important, yet not fully resolved, role of MST in the context of stress-induced cardiovascular disease.

Furthermore, the $\mathrm{H}_{2} \mathrm{~S}$ and oxytocin system are both reported to be involved in mitochondrial functioning. The literature on exact mechanisms remains limited, but several studies suggest a direct interaction between oxytocin and mitochondria affecting mitochondrial bioenergetics [30] in, e.g., ischemia-reperfusion-injury [31] and early-life-stress [11]. We cannot say for certain what the implications of the apparent inability to upregulate complex IV activity in $\triangle \mathrm{MST}$ in response to injury are, since our observations are based on the non-demonstrated assumption that naive $\mathrm{wt}$ and naive $\Delta \mathrm{MST}$ mice have comparable complex IV activity; nor can we say whether this is regulated by the loss of either MST, CSE, OTR, or a combination thereof. Nevertheless, our findings confirm previously published studies suggesting an interaction of the $\mathrm{H}_{2} \mathrm{~S}$ and oxytocin system $[1,14,15]$. Because $\mathrm{H}_{2} \mathrm{~S}$ and oxytocin are considered to be cardioprotective [32-34], loss of the aforementioned proteins points to cardiovascular dysfunction. We recently showed the mutual interaction of $\mathrm{H}_{2} \mathrm{~S}$ and the neuroendocrine oxytocin systems in cardiac injury [15]. OTR and CSE are constitutively expressed in the heart $[15,33]$ and are reported to be cardioprotective $[32,33,35-37]$. 
CSE is the most important producer of endogenous $\mathrm{H}_{2} \mathrm{~S}$ in the cardiovascular system [38]. In recent studies on resuscitated, co-morbid septic pigs displaying a similar reduction of cardiac output as patients with coronary artery disease, we were able to show reduced tissue CSE expression in the coronary artery [34], kidney [25], and heart [32], which was associated with increased troponin levels and CSE mRNA (compensating for reduced tissue protein expression) and reduced cardiac OTR expression [39]. In addition, Wang et al. propose that $\mathrm{H}_{2} \mathrm{~S}$ and $\mathrm{OT}$ are able to both act via nitric oxide (NO) regulation, and that CSE might be able to mediate cardioprotection by OTR upregulation and activation of the reperfusion injury salvage kinase (RISK) pathway [40].

Coletti et al. showed, in a model of fluid shift, that water deprivation increased endogenous $\mathrm{H}_{2} \mathrm{~S}$ production, and that exogenous $\mathrm{H}_{2} \mathrm{~S}$ administration $\left(\mathrm{Na}_{2} \mathrm{~S}\right)$ stimulated cerebral oxytocin release by inhibiting the NO system [41]. More recently, $\mathrm{H}_{2} \mathrm{~S}$, triggered by acute hyperosmolality, was described as a positive regulator of OT, in contrast to NO, which played the role of a negative neuroendocrine modulator of OT [42]. Both $\mathrm{H}_{2} \mathrm{~S}$ and OT are also known as vasoactive mediators, and are therefore implicated in regulating circulating blood volume, blood pressure [43-52] and the heart rate [1,53,54]. Our results confirm our hypothesis that HS, a pronounced fluid shift, leads to a downregulation of CSE and OTR in the heart (see Figure 2B,D). Cardiac OTR and CSE directly correlated in wt and $\triangle \mathrm{MST}$ animals in the naive state, as well as after injury (see Figure 2E). Although in this study we have no data for their expression in the brain, in a porcine model of HS we were able to co-localize the proteins in the hypothalamus and the corresponding magnocellular neurons [1], where they are reported to interact in response to fluid shifts [41]. The effects of $\triangle \mathrm{MST}$ on the regulation of cerebral levels of CSE and OTR expression warrant further investigations. In retrospect, a limitation of this study is that we did not evaluate the CBS expression, which could provide an interesting piece of the puzzle and should be evaluated in future studies.

\section{Conclusions}

In a clinically relevant, resuscitated mouse model, naive and injured $\triangle$ MST mice had a reduction of cardiac CSE and OTR expression. Injured $\triangle \mathrm{MST}$ mice had similar levels of mitochondrial complex IV activity to wt naive animals, whereas in injured wt animals higher complex IV activity was observed as an adaptive response. Hemorrhagic shock, a dramatic fluid shift, led to cardiac CSE and OTR downregulation in wt animals, confirming similar previous results in the injured mouse heart [14,15]. Additional confirmation of their interaction is the fact that their expression was directly correlated in animals in both the naive state as well as post-injury, even though the exact mechanisms of an interaction between the $\mathrm{H}_{2} \mathrm{~S}$ and OT system have yet to be clarified. Previously, we reported that exogenous $\mathrm{H}_{2} \mathrm{~S}$ administration (GYY4137) mediated an upregulation of cardiac OTR expression, which was accompanied by restored blood glucose levels and mean arterial pressure [15]. Taken together with the findings presented here, this study suggests that exogenous $\mathrm{H}_{2} \mathrm{~S}$ administration may be a therapeutic option to mediate cardioprotection from both psychological and physical trauma by OTR upregulation.

Author Contributions: Conceptualization, O.M. and T.M.; methodology, E.C.; formal analysis, T.M. and O.M.; investigation, B.T. and N.D.; resources, P.R. and C.S.; writing-original draft preparation, B.T.; writing — review and editing, O.M., T.M., C.S., and P.R..; visualization, T.M. and O.M.; supervision, P.R.; project administration, P.R. and O.M.; funding acquisition, P.R. and T.M. All authors have read and agreed to the published version of the manuscript.

Funding: This research was funded by the Deutsche Forschungsgemeinschaft (DFG; German Research Foundation), project number 251293561, SFB 1149 to P.R. and T.M. 
Institutional Review Board Statement: The study protocol was authorized by the federal authorities for animal research of the Regierungspräsidium Tübingen (approved animal experimentation number: 1190) Baden-Württemberg, Germany, and the Animal Care Committee of the University of Ulm, Baden-Württemberg, Germany. Experiments were performed in adherence with the National Institutes of Health Guidelines on the Use of Laboratory Animals and the European Union "Directive 2010/63 EU on the protection of animals used for scientific purposes".

Informed Consent Statement: Not applicable.

Data Availability Statement: Data is contained within the article.

Acknowledgments: We thank Rosy Engelhardt, Andrea Seifritz, Sandra Kress, and Michael Gröger for technical assistance and surgical procedures.

Conflicts of Interest: The authors declare no conflict of interest.

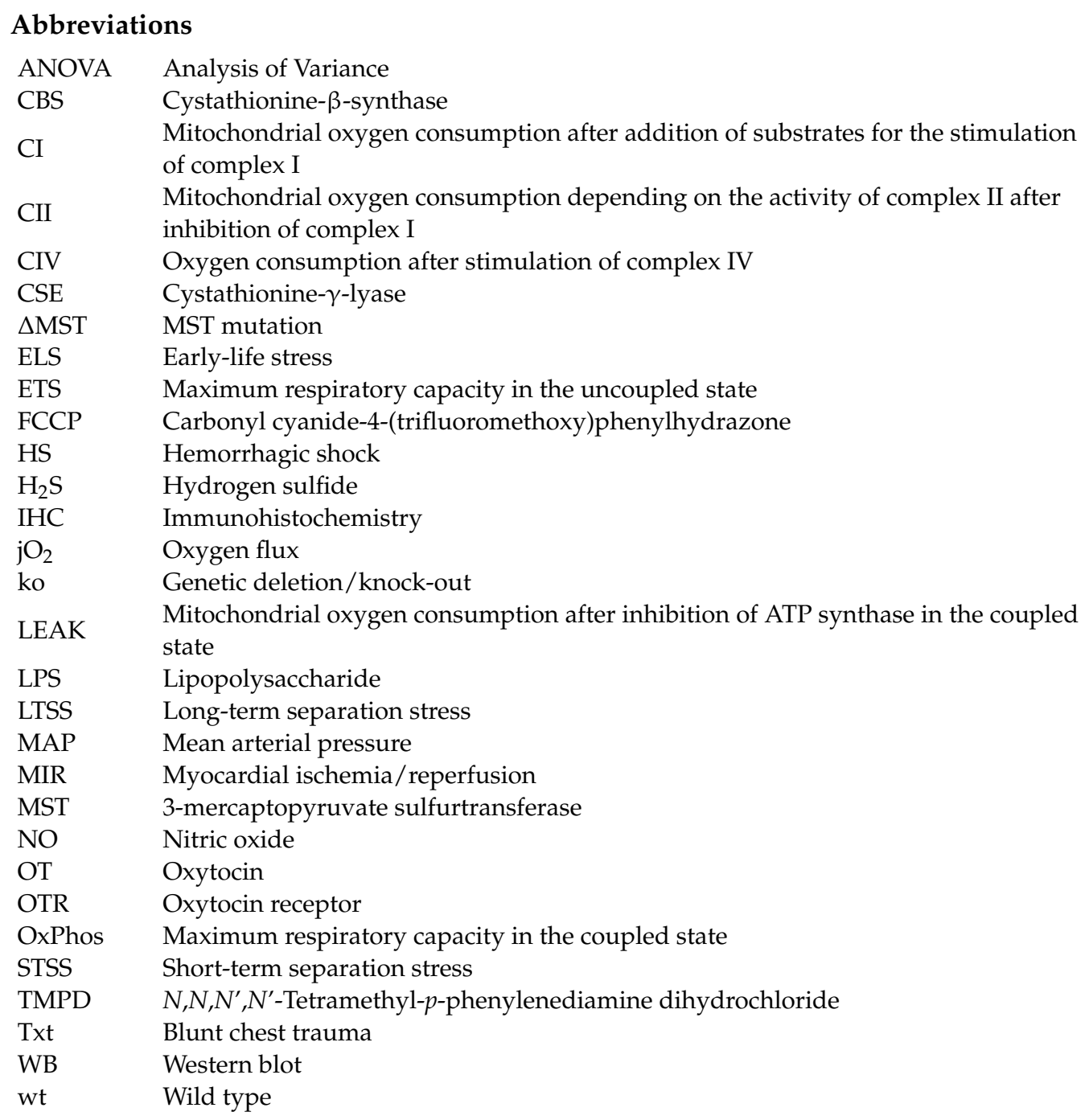

\section{References}

1. Denoix, N.; McCook, O.; Ecker, S.; Wang, R.; Waller, C.; Radermacher, P.; Merz, T. The Interaction of the Endogenous Hydrogen Sulfide and Oxytocin Systems in Fluid Regulation and the Cardiovascular System. Antioxidants 2020, 9, 748. [CrossRef] [PubMed]

2. Peleli, M.; Bibli, S.I.; Li, Z.; Chatzianastasiou, A.; Varela, A.; Katsouda, A.; Zukunft, S.; Bucci, M.; Vellecco, V.; Davos, C.H.; et al. Cardiovascular phenotype of mice lacking 3-mercaptopyruvate sulfurtransferase. Biochem. Pharmacol. 2020, $176,113833$. [CrossRef] [PubMed]

3. Nagahara, N.; Nagano, M.; Ito, T.; Shimamura, K.; Akimoto, T.; Suzuki, H. Antioxidant enzyme, 3-mercaptopyruvate sulfurtransferaseknockout mice exhibit increased anxiety-like behaviors: A model for human mercaptolactate-cysteine disulfiduria. Sci. Rep. 2013, 3 , 1986. [CrossRef] [PubMed] 
4. Gröger, M.; Wepler, M.; Wachter, U.; Merz, T.; McCook, O.; Kress, S.; Lukaschewski, B.; Hafner, S.; Huber-Lang, M.; Calzia, E.; et al. The Effects of Genetic 3-Mercaptopyruvate Sulfurtransferase Deficiency in Murine Traumatic-Hemorrhagic Shock. Shock 2019, 51, 472-478. [CrossRef] [PubMed]

5. Wang, Q.; Wang, X.L.; Liu, H.R.; Rose, P.; Zhu, Y.Z. Protective effects of cysteine analogues on acute myocardial ischemia: Novel modulators of endogenous $\mathrm{H}_{2} \mathrm{~S}$ production. Antioxid. Redox. Signal. 2010, 12, 1155-1165. [CrossRef]

6. Kondo, K.; Bhushan, S.; King, A.L.; Prabhu, S.D.; Hamid, T.; Koenig, S.; Murohara, T.; Predmore, B.L.; Gojon, G., Sr.; Gojon, G., Jr.; et al. $\mathrm{H}_{2} \mathrm{~S}$ protects against pressure overload-induced heart failure via upregulation of endothelial nitric oxide synthase. Circulation 2013, 127, 1116-1127. [CrossRef]

7. Chen, Y.; Zhang, F.; Yin, J.; Wu, S.; Zhou, X. Protective mechanisms of hydrogen sulfide in myocardial ischemia. J. Cell. Physiol. 2020, 235, 9059-9070. [CrossRef]

8. $\quad$ Ellmers, L.J.; Templeton, E.M.; Pilbrow, A.P.; Frampton, C.; Ishii, I.; Moore, P.K.; Bhatia, M.; Richards, A.M.; Cameron, V.A. Hydrogen Sulfide Treatment Improves Post-Infarct Remodeling and Long-Term Cardiac Function in CSE Knockout and Wild-Type Mice. Int. J. Mol. Sci. 2020, 21, 4284. [CrossRef]

9. Szabo, C.; Ransy, C.; Módis, K.; Andriamihaja, M.; Murghes, B.; Coletta, C.; Olah, G.; Yanagi, K.; Bouillaud, F. Regulation of mitochondrial bioenergetic function by hydrogen sulfide. Part I. Biochemical and physiological mechanisms. Br. J. Pharmacol. 2014, 171, 2099-2122. [CrossRef]

10. Denoix, N.; McCook, O.; Scheuerle, A.; Kapapa, T.; Hoffmann, A.; Gündel, H.; Waller, C.; Radermacher, P.; Merz, T. Brain histology and immunohistochemistry after resuscitation from hemorrhagic shock in swine with pre-existing atherosclerosis: Effects of sodium thiosulfate $\left(\mathrm{Na}_{2} \mathrm{~S}_{2} \mathrm{O}_{3}\right)$. Front. Pharmacol. 2021, under review.

11. Amini-Khoei, H.; Amiri, S.; Mohammadi-Asl, A.; Alijanpour, S.; Poursaman, S.; Haj-Mirzaian, A.; Rastegar, M.; Mesdaghinia, A.; Banafshe, H.R.; Sadeghi, E.; et al. Experiencing neonatal maternal separation increased pain sensitivity in adult male mice: Involvement of oxytocinergic system. Neuropeptides 2017, 61, 77-85. [CrossRef]

12. Albus, C.; Herrmann-Lingen, C.; Jensen, K.; Hackbusch, M.; Münch, N.; Kuncewicz, C.; Grilli, M.; Schwaab, B.; Rauch, B. For the German Society of Cardiovascular Prevention \& Rehabilitation (DGPR). Additional effects of psychological interventions on subjective and objective outcomes compared with exercise-based cardiac rehabilitation alone in patients with cardiovascular disease: A systematic review and meta-analysis. Eur. J. Prev. Cardiol. 2019, 26, 1035-1049.

13. D'Andrea, W.; Sharma, R.; Zelechoski, A.D.; Spinazzola, J. Physical health problems after single trauma exposure: When stress takes root in the body. J. Am. Psychiatr. Nurses Assoc. 2011, 17, 378-392. [CrossRef] [PubMed]

14. Wigger, D.C.; Gröger, N.; Lesse, A.; Krause, S.; Merz, T.; Gündel, H.; Braun, K.; McCook, O.; Radermacher, P.; Bock, J.; et al. Maternal Separation Induces Long-Term Alterations in the Cardiac Oxytocin Receptor and Cystathionine $\gamma$-Lyase Expression in Mice. Oxid. Med. Cell Longev. 2020, 2020. [CrossRef] [PubMed]

15. Merz, T.; Lukaschewski, B.; Wigger, D.; Rupprecht, A.; Wepler, M.; Gröger, M.; Hartmann, C.; Whiteman, M.; Szabo, C.; Wang, R.; et al. Interaction of the hydrogen sulfide system with the oxytocin system in the injured mouse heart. Intensive Care Med. Exp. 2018, 6, 41. [CrossRef] [PubMed]

16. Veenema, A.H.; Bredewold, R.; Neumann, I.D. Opposite effects of maternal separation on intermale and maternal aggression in C57BL/ 6 mice: Link to hypothalamic vasopressin and oxytocin immunoreactivity. Psychoneuroendocrinology 2007, 32, 437-450. [CrossRef] [PubMed]

17. Wang, C.-J.; Chen, Y.-C.; Chien, T.-H.; Chang, H.-Y.; Chen, Y.-H.; Chien, C.-Y.; Huang, T.-S. Impact of comorbidities on the prognoses of trauma patients: Analysis of a hospital-based trauma registry database. PLoS ONE 2018, 13, e0194749. [CrossRef] [PubMed]

18. Ferraris, V.A.; Ferraris, S.P.; Saha, S.P. The relationship between mortality and preexisting cardiac disease in 5971 trauma patients. J. Trauma Acute Care Surg. 2010, 69, 645-652.

19. Auxéméry, Y. Post-traumatic psychiatric disorders: PTSD is not the only diagnosis. Presse. Med. 2018, 47, 423-430. [CrossRef] [PubMed]

20. Gero, D.; Ahmad, A.; Brunyanszki, A.; Olah, G.; Szczesny, B.; Szabo, C. 3-Mercaptopyruvate sulfurtransferase deficient mice show accelerated glucose uptake and a dysregulated metabolic profile. Nitric Oxide 2015, 47, S35-S36. [CrossRef]

21. Ahmad, A.; Gerö, D.; Ola, G.; Szabo, C. Effect of endotoxemia in mice genetically deficient in cystathionine- $\gamma$-lyase, cystathionine$\beta$-synthase or 3-mercaptopyruvate sulfurtransferase. Int. J. Mol. Med. 2016, 38, 1683-1692. [CrossRef] [PubMed]

22. Wepler, M.; Merz, T.; Wachter, U.; Vogt, J.; Calzia, E.; Scheuerle, A.; Möller, P.; Gröger, M.; Kress, S.; Fink, M.; et al. The Mitochondria-Targeted $\mathrm{H}_{2} \mathrm{~S}$-Donor AP39 in a Murine Model of Combined Hemorrhagic Shock and Blunt Chest Trauma. Shock 2019, 52, 230-239. [CrossRef] [PubMed]

23. Hartmann, C.; Gröger, M.; Noirhomme, J.P.; Scheuerle, A.; Möller, P.; Wachter, U.; Huber-Lang, M.; Nussbaum, B.; Jung, B.; Merz, T.; et al. In-Depth Characterization of the Effects of Cigarette Smoke Exposure on the Acute Trauma Response and Hemorrhage in Mice. Shock 2019, 51, 68-77. [CrossRef] [PubMed]

24. Merz, T.; Vogt, J.A.; Wachter, U.; Calzia, E.; Szabo, C.; Wang, R.; Radermacher, P.; McCook, O. Impact of hyperglycemia on cystathionine- $\gamma$-lyase expression during resuscitated murine septic shock. Intensive Care Med. Exp. 2017, 5, 1-14. [CrossRef]

25. Merz, T.; Wepler, M.; Nußbaum, B.; Vogt, J.; Calzia, E.; Wang, R.; Szabo, C.; Radermacher, P.; McCook, O. Cystathionine- $\gamma$-lyase expression is associated with mitochondrial respiration during sepsis-induced acute kidney injury in swine with atherosclerosis. Intensive Care Med. Exp. 2018, 6, 43. [CrossRef] 
26. Nagahara, N.; Ito, T.; Kitamura, H. Tissue and subcellular distribution of mercaptopyruvate sulfurtransferasein the rat: Confocal laser fluorescence and immunoelectron microscopic studies combined with biochemicalanalysis. Histochem. Cell Biol. 1998, 110, 243-250. [CrossRef]

27. Krause, S.; Boeck, C.; Gumpp, A.M.; Rottler, E.; Schury, K.; Karabatsiakis, A.; Buchheim, A.; Gündel, H.; Kolassa, I.T.; Waller, C. Child Maltreatment Is Associated with a Reduction of the Oxytocin Receptor in Peripheral Blood Mononuclear Cells. Front. Psychol. 2018, 9, 173. [CrossRef]

28. Ahmad, A.; Druzhyna, N.; Szabo, C. Effect of 3-mercaptopyruvate sulfurtransferase deficiency on the development of multiorgan failure, inflammation and wound healing in mice subjected to burn injury. J. Burn. Care Res. 2019, 40, 148-156. [CrossRef]

29. Li, Z.; Xia, H.; Sharp, T.; Hidalgo, H.; Nagahara, N.; Elrod, J.W.; Lefer, D.J. Deficiency of 3-Mercaptopyruvate Sulfurtransferase Results in Impaired Mitochondrial Function and Increased Heart Failure Severity. Circulation 2019, 140, A15987.

30. Bordt, E.A.; Smith, C.J.; Demarest, T.G.; Bilbo, S.D.; Kingsbury, M.A. Mitochondria, Oxytocin, and Vasopressin: Unfolding the Inflammatory Protein Response. Neurotox. Res. 2019, 36, 239-256. [CrossRef] [PubMed]

31. Kaneko, Y.; Pappas, C.; Tajiri, N.; Borlongan, C.V. Oxytocin modulates GABAAR subunits to confer neuroprotection in stroke in vitro. Sci. Rep. 2016, 6, 35659. [CrossRef]

32. Nussbaum, B.L.; McCook, O.; Hartmann, C.; Matallo, J.; Wepler, M.; Antonucci, E.; Kalbitz, M.; Huber-Lang, M.; Georgieff, M.; Calzia, E.; et al. Left ventricular function during porcine resuscitated septic shock with pre-existing atherosclerosis. Intensive Care Med. Exp. 2016, 4, 14. [CrossRef]

33. Gutkowska, J.; Jankowski, M.; Antunes-Rodrigues, J. The role of oxytocin in cardiovascular regulation. Braz. J. Med. Biol. Res. 2014, 47, 206-214. [CrossRef] [PubMed]

34. Merz, T.; Stenzel, T.; Nussbaum, B.; Wepler, M.; Szabo, C.; Wang, R.; Radermacher, P.; McCook, O. Cardiovascular disease and resuscitated septic shock lead to the downregulation of the $\mathrm{H}_{2} \mathrm{~S}$ producing enzyme cystathionine- $\gamma$-lyase in the porcine coronary artery. Intensive Care Med. Exp. 2017, 5, 17. [CrossRef] [PubMed]

35. Moghimian, M.; Faghihi, M.; Karimian, S.M.; Imani, A.; Houshmand, F.; Azizi, Y. The role of central oxytocin in stress-induced cardioprotection in ischemic-reperfused heart model. J. Cardiol. 2013, 61, 79-86. [CrossRef] [PubMed]

36. Elrod, R.J.; Gozal, Y.; Navot, N.; Zuo, Z. Activation of adenosine triphosphate-regulated potassium channels during reperfusion restores isoflurane postconditioning-induced cardiac protection in acutely hyperglycemic rabbits. Anesthesiology 2015, 122, 1299_ 1311.

37. Jin, S.; Teng, X.; Xiao, L.; Xue, H.; Guo, Q.; Duan, X.; Chen, Y.; Wu, Y. Hydrogen sulfide ameliorated L-NAME-induced hypertensive heart disease by the Akt/eNOS/NO pathway. Exp. Biol. Med. 2017, 242, 1831-1841. [CrossRef]

38. Wang, R. Physiological implications of hydrogen sulfide: A whiff exploration that blossomed. Physiol. Rev. 2012, 92, 791-896. [CrossRef]

39. Merz, T.; Denoix, N.; Wigger, D.; Waller, C.; Wepler, M.; Vettorazzi, S.; Tuckermann, J.; Radermacher, P.; McCook, O. The Role of Glucocorticoid Receptor and Oxytocin Receptor in the Septic Heart in a Clinically Relevant, Resuscitated Porcine Model With Underlying Atherosclerosis. Front. Endocrinol. 2020, 11, 299. [CrossRef]

40. Wang, P.; Wang, S.C.; Yang, H.; Lv, C.; Jia, S.; Liu, X.; Wang, X.; Meng, D.; Qin, D.; Zhu, H.; et al. Therapeutic Potential of Oxytocin in Atherosclerotic Cardiovascular Disease: Mechanisms and Signaling Pathways. Front. Neurosci. 2019, 13, 454. [CrossRef]

41. Coletti, R.; Almeida-Pereira, G.; Elias, L.L.K.; Antunes-Rodrigues, J.E. Effects of hydrogen sulfide $\left(\mathrm{H}_{2} \mathrm{~S}\right)$ on water intake and vasopressin and oxytocin secretion induced by fluid deprivation. Horm. Behav. 2015, 67, 12-20. [CrossRef] [PubMed]

42. Coletti, R.; de Lima, J.; Vechiato, F.; de Oliveira, F.L.; Debarba, L.K.; Almeida-Pereira, G.; Elias, L.; Antunes-Rodrigues, J. Nitric oxide acutely modulates hypothalamic and neurohypophyseal carbon monoxide and hydrogen sulphide production to control vasopressin, oxytocin and atrial natriuretic peptide release in rats. J. Neuroendocr. 2019, 31, e12686. [CrossRef]

43. Yang, G.; Wu, L.; Jiang, B.; Yang, W.; Qi, J.; Cao, K.; Meng, Q.; Mustafa, A.K.; Mu, W.; Zhang, S.; et al. H ${ }_{2} \mathrm{~S}$ as a physiologic vasorelaxant: Hypertension in mice with deletion of cystathionine gamma-lyase. Science 2008, 322, 587-590. [CrossRef]

44. Thibonnier, M.; Conarty, D.M.; Preston, J.A.; Plesnicher, C.L.; Dweik, R.A.; Erzurum, S.C. Human vascular endothelial cells express oxytocin receptors. Endocrinology 1999, 140, 1301-1309. [CrossRef]

45. Jankowski, M.; Wang, D.; Hajjar, F.; Mukaddam-Daher, S.; McCann, S.M.; Gutkowska, J. Oxytocin and its receptors are synthesized in the rat vasculature. Proc. Natl. Acad. Sci. USA 2000, 97, 6207-6211. [CrossRef]

46. Menaouar, A.; Florian, M.; Wang, D.; Danalache, B.; Jankowski, M.; Gutkowska, J. Anti-hypertrophic effects of oxytocin in rat ventricular myocytes. Int. J. Cardiol. 2014, 175, 38-49. [CrossRef]

47. Mancardi, D.; Pla, A.F.; Moccia, F.; Tanzi, F.; Munaron, L. Old and new gasotransmitters in the cardiovascular system: Focus on the role of nitric oxide and hydrogen sulfide in endothelial cells and cardiomyocytes. Curr. Pharm. Biotechnol. 2011, 12, 1406-1415. [CrossRef]

48. Holst, S.; Uvnas-Moberg, K.; Petersson, M. Postnatal oxytocin treatment and postnatal stroking of rats reduce blood pressure in adulthood. Auton. Neurosci. 2002, 99, 85-90. [CrossRef]

49. Całka, J. The role of nitric oxide in the hypothalamic control of LHRH and oxytocin release, sexual behavior and aging of the LHRH and oxytocin neurons. Folia Histochem. Cytobiol. 2006, 44, 3-12.

50. Petersson, M.; Uvnas-Moberg, K. Postnatal oxytocin treatment of spontaneously hypertensive male rats decreases blood pressure and body weight in adulthood. Neurosci. Lett. 2008, 2, 166-169. [CrossRef] 
51. Ali, M.Y.; Ping, C.Y.; Mok, Y.Y.P.; Ling, L.; Whiteman, M.; Bhatia, M.; Moore, P.K. Regulation of vascular nitric oxide in vitro and in vivo: A new role for endogenous hydrogen sulphide? Br. J. Pharmacol. 2006, 149, 625-634. [CrossRef]

52. Hosoki, R.; Matsuki, N.; Kimura, H. The possible role of hydrogen sulfide as an endogenous smooth muscle relaxant in synergy with nitric oxide. Biochem. Biophys. Res. Commun. 1997, 237, 527-531. [CrossRef]

53. Dawe, G.S.; Han, S.P.; Bian, J.S.; Moore, P.K. Hydrogen sulphide in the hypothalamus causes an ATP-sensitive K channeldependent decrease in blood pressure in freely moving rats. Neuroscience 2008, 152, 169-177. [CrossRef] [PubMed]

54. Liu, W.Q.; Chai, C.; Li, X.Y.; Yuan, W.J.; Wang, W.Z.; Lu, Y. The cardiovascular effects of central hydrogen sulfide are related to $\mathrm{K}_{\text {ATP }}$ channels activation. Physiol. Res. 2011, 60, 729-738. [CrossRef] [PubMed] 